\title{
SOBRE EL ORIGEN DEL SER HUMANO
}

\author{
Rafael Alvira, \\ Universidad de Navarra.
}

\begin{abstract}
Resumen: Orígenes del hombre. La singularidad del ser humano de Francisco Rodríguez Valls enfoca el difícil tema de la antropología con un uso muy serio de los recursos científicos y filosóficos disponibles, y con originalidad. Las claves interpretativas actuales evolucionismo y libertad - las trata con ponderación: las acepta, pero con matices interpretativos que se alejan de los reduccionismos hoy frecuentes.

Palabras clave: Antropología, Evolución, Libertad, Cultura, Dignidad.

On the origin of human being.

Abstract: Origins of man. The singularity of human being by Francisco Rodríguez Valls addresses the difficult issue of anthropology with a very serious use of the available scientific and philosophical resources, and with originality. The current interpretative keys —evolutionism and freedom — treats them with weighting: he accepts them, but with interpretative nuances that move away from the reductionism that is prevalent today.

Keywords: Anthropology, Evolution, Freedom, Culture, Dignity.

Recibido: 28 de octubre de 2019. Aprobado: 15 de noviembre de 2019.
\end{abstract}

\section{Proemio}

Orígenes del hombre. La singularidad del ser humano, de Francisco Rodríguez Valls, es un libro serio, rico de pensamiento y de calidad científica contrastada. Bien escrito y bien articulado, muestra unos conocimientos muy amplios tanto de la base científico-natural de la antropología, como del acercamiento filosófico a ella. Esto no es fácil de encontrar en las publicaciones al uso, sobre todo si se le añade — como es el caso— una ponderación de juicio y una actitud de sincera búsqueda de la verdad, sin dejarse llevar por el apasionamiento que este tema suscita.

Entrar en la discusión antropológica actual implica aceptar y dar por descontados dos dogmas de ella, a saber, el evolucionismo en lo "científicobiológico" y el carácter central de la libertad en lo "espiritual", tomando el concepto de "espiritual" en su sentido más genérico. Son dos conceptos que 
se han convertido también en lugares comunes de nuestra cultura occidental.

Es mérito señalado, a mi juicio, de Francisco Rodríguez Valls, el haber escrito un texto muy equilibrado y bien argumentado sobre antropología, que aparte de su valor expositivo, entra en la discusión actual mediante el uso nuclear de esos dos conceptos. En lo que sigue, me parece interesante, más que entrar en pequeñas discusiones de detalle, exponer una argumentación antropológica en la que ambos conceptos juegan un papel, pero no nuclear. Rodríguez Valls subraya muy bien la necesidad de distinguir entre el "evolucionismo científico" y el "filosófico", pero es que tengo mis dudas también sobre el científico. Y es muy matizado al hablar de la libertad, pero es que, para mí, la idea habitual hoy en uso de libertad ha de ser revisada.

\section{El inicio del conocimiento humano}

El ser humano despierta su conocimiento de modo distinto según lo dirija hacia otras realidades o hacia sí mismo. El mundo que nos rodea está ante nosotros, es "objetivo", y nos arrastra inmediatamente hacia él, nos arroba en la admiración. Al experimentar después las dificultades que nos plantea, surge en nosotros el deseo de conocerlo más a fondo, el deseo de saber, y nos sentimos empujados a preguntar. En cambio, a nosotros mismos nos conocemos primero de modo "connatural", "subjetivo", no estamos ante nosotros mismos todavía, y por eso experimentamos primero las dificultades de nuestro vivir, las cuales entonces nos abren el deseo de conocernos más a fondo, de preguntarnos por nosotros mismos, y se inicia la propia admiración.

En otros términos: si el acto, tan profundo, de agradecer es subsiguiente al de reconocer la recepción de un don, el agradecimiento ante el mundo que nos rodea es instintivo ya en la admiración que nos suscita, mientras que el agradecimiento ante nuestro propio ser es tardío, y a veces ni siquiera llega a producirse. Desde el primer momento nos asombramos del mundo, y en la medida en que desarrollamos un verdadero saber acerca de él, el 
asombro crece. Por el contrario, en la medida en que nos vamos conociendo más, de verdad, a nosotros mismos, lo habitual es que aumente algún descontento de cada persona no tanto sobre ella en cuanto objetivada, sino principalmente sobre ella misma. Por eso se ha entendido siempre como deficiente la figura del "Narciso".

Esto nos empuja a pensar que lo que nos es dado, aquello que percibo objetivamente, ha de tener un donante que sea tan maravilloso al menos como la calidad de su regalo; por el contrario, el yo me resulta de entrada más bien deficiente y además inapresable: no puedo, en principio, ni conocerme ni dominarme y, como resultado, no tengo razón para admirarme. En consecuencia, se puede decir que algo va mal en mi vida si, por el contrario, me va disgustando el mundo y me voy gustando narcisistamente a mí mismo, por la simple razón de que cada paso que doy en el conocimiento del mundo tiene como resultado nuevos descubrimientos maravillosos, mientras que cada nuevo descubrimiento de mi yo me muestra una carencia o un fallo más.

\section{El recurso a Dios}

Estas sencillas observaciones son las que han llevado a infinidad de personas y a no pocos de los "pocos sabios que en el mundo han sido", a primar al donante sobre el yo. Si yo no parezco ser el autor de mi vida, no puedo ni conocerla ni dominarla perfectamente, pues sólo quien crea conoce y domina perfectamente. La consecuencia de esta consideración no es, con todo, unívoca.

Puedo enfadarme por mi condición de haber sido creado sin mi permiso; puedo pensar que parezco creado, pero en realidad no lo soy; o puedo tomar la actitud de agradecimiento, que es la esencia de la religión. La fe es clave en ella, porque como me siento creado por un autor que no conozco, pero cuyo don objetivo — el mundo que me rodea y el hecho de mi vivir- me maravilla, confío, creo en Él, y procuro conocerlo más a fondo a través del estudio de la misma creación. Y ese conocimiento fortalece mi fe, pero sin 
embargo no la convierte ni puede convertirla en puro conocimiento objetivo.

A partir de lo dicho, se presentan algunas dificultades. De un lado, el mencionado autor-donante no se hace presente a los sentidos, aunque esta dificultad queda relativizada por el entendimiento, que aprecia la imposibilidad de ser creador y creatura al mismo tiempo: percibimos sólo las creaturas, aunque no es poco, pues su maravilla nos lleva al creador. La inteligencia, por su parte, descubre al donante en tanto que autor, pero ser autor no es idéntico con ser. Todo sumado, aceptamos que ha de haber un autor-donante maravilloso, pero queda un espacio para la duda. ¿Por qué? Porque la seguridad definitiva en la relación con otro ser sólo puede lograrse mediante el trato existencial.

Ahora bien, las relaciones existenciales tienen por base lo sensible y lo inteligible, pero no se dan sin la presencia de la voluntad personal. Es esa voluntad el poder "ec-stático" por excelencia, que me "saca fuera de mi" con el resultado paradójico de lograr que me "encuentre a mi mismo". Esa salida sólo es posible de modo pleno cuando otro ser me permite "entrar en él”. Por eso la relación entre dos amigos o dos personas que se aman implica un conocimiento sensible e inteligible del otro, pero además una confianza — $\mathrm{fe}$ - añadida, gracias a la cual me relaciono existencialmente con él en vez de tomar precauciones frente a él.

Nuestro problema con respecto a la existencia de un creador, un Dios, cuyo ser entendemos como necesario, es, en la dimensión teórica, que al no conocerlo tal como es, nos resulta difícil iniciar un trato que se pueda llamar existencial, pues no sabemos bien cómo hemos de llevarlo a cabo; y, en la dimensión práctica, que quien regala algo maravilloso ha de ser con seguridad bueno, pero encontramos mucho mal en el mundo y más aún en nosotros mismos. La cuestión es tan profunda que —a mi juicio— sólo se puede solucionar con la aparición existencial de un hombre que es Dios y es bueno. Sólo un ser así puede fortalecer nuestra fe existencial en un Ser cuya realidad suponemos cierta. 
Si no se acepta la divinidad de Cristo, la consecuencia del primer problema es la posibilidad de olvidar a Dios, al no tratarlo, o bien de tener con Él un trato tan defectuoso como la idea igualmente defectuosa que de Él algunos se hacen. La consecuencia del segundo problema es más grave y consiste en la posibilidad de desconfiar de Dios; desde aquí, es posible o bien enfrentarse a Él, o bien, al modo de Leibniz, intentar "salvar" su bondad al rechazar que tenga culpa alguna en el mal.

Este último punto es de la máxima dificultad. Si Dios crea todo ¿cómo es posible que no cree también el mal? Pero, a su vez, ¿cómo puede un Dios bueno — la bondad es por esencia un añadido real, y Dios da, regala— crear el mal?

\section{El tema de la libertad}

La solución que ofrece la tradición bíblica es conocida: bien y mal son un producto exclusivo de una libertad dueña de sí misma. El contenido de la libertad es: actividad, apertura y posesión, características que de diferentes modos se dan en muchos seres, pero la libertad poseedora, dueña de sí, es propia en este mundo sólo del ser humano, y se encierra en la capacidad de juzgar.

La Biblia, como representante de la gran tradición del pensamiento religioso, sostiene entonces que Dios nos ha dado todo, incluida esa capacidad de juicio, pero el ejercicio de esa capacidad es lo que está exclusivamente en manos de quien la tiene. Por eso el ser libre es quien puede responder a la pregunta: ¿por qué lo decidiste y lo hiciste? Es decir, en la decisión libre el ser humano es el único ser de este mundo que es "creador". Esa es seguramente una de las razones por las que la Biblia dice también que está hecho "a imagen de Dios".

Con todo, el ser humano sólo puede juzgar a partir de lo dado. Es decir, Dios es libre plenamente al crear, ya que no tiene nada previo, sino que Él lo pone; por el contrario, el juicio humano es libre, sí, pero está condicionado por lo ya dado. $\mathrm{Y}$ desde esta tesis, se abren al menos tres posibilidades. 
Primera posibilidad. Una es afirmar que los condicionantes son determinantes, tesis que anula la libertad. Es la idea de los biólogos deterministas que intentan mostrar que todo lo que el ser humano hace es consecuencia de procesos biológicos: nos imaginamos libres, pero no lo somos. No es este el lugar para discutir una tesis que, con todo, no ha podido justificarse ni siquiera de manera empírica.

Segunda posibilidad. Otra postura es la de sostener que la libertad puede acabar dominando por completo los condicionantes. La tesis transhumanista, hoy en el escaparate, sostiene que es posible el dominio progresivo de la libertad sobre sus condicionantes. Interpreta la libertad humana como poder total, puede hacer lo que quiera con lo dado, con la "materia", pero se enfrenta con el problema de que no es un poder absoluto, por la simple razón de que todo poder humano se ejerce sobre algo dado: no somos capaces de sacar algo desde una "nada absoluta". Podremos quizás todo, pero no podemos absolutamente. Ello implica que estamos, de modo irremediable, condicionados por una materialidad que nos antecede y que no somos capaces de poner.

La pregunta es entonces: ¿Quién ha hecho esa materia, quien la ha puesto? ¿No la ha hecho nadie? La respuesta transhumanista, si quiere ser consecuente, ha de ser que no, lo que muestra su carácter de culminación del progresismo. Según esta tesis, el ser humano se ha dado cuenta por fin de que es el "Rey delMundo", casi lo mismo, por tanto, que la tesis bíblica, según la cual el ser humano es el "Rey de este mundo".

De todos modos, la tesis progresista - como no podía ser de otro modoes una fe: aunque sea de mala gana, hemos de aceptar nuestra creencia en que el mundo no lo ha hecho nadie; lo creemos porque no lo podemos demostrar. Y es que la exigencia natural de nuestra razón, que pide una explicación definitiva, sólo puede ser respondida por un acto de fe. El "saber absoluto del absoluto" hegeliano ni sabe por qué se sabe absolutamente, ni porqué ha comenzado a saberse, ni la inmensidad de detalles del saber. La filosofía puede ser "un cierto y modesto saber absoluto de lo absoluto", pero en modo alguno, frente a lo que dice Hegel, está por encima de la fe: 
no puede. Más bien, como es claro, está a su servicio: creemos "desde" lo que conocemos.

En cualquier caso, no hay duda de que, según la tesis moderna, la libertad entendida como poder es el núcleo constitutivo, "especificante", de lo humano y por tanto de cada ser humano. Y como en la tradición religiosa bíblica el primer acto diferenciador del ser humano fue su libre elección de no obedecer a Dios, parece en consecuencia que todos están de acuerdo: lo específico antropológico es la libertad. Democracia para todos. Así se sostiene también en la notable obra "Orígenes del hombre", de Rodríguez Valls. Esta tesis está de hecho no sólo compartida por muchos hoy, sino que es elemento nuclear de la cultura en la que vivimos.

Objeción a esta segunda posibilidad y propuesta de solución

Con todo, no es seguro que sea así. En primer lugar, la libertad — como ya va apuntado aquí - es una realidad tridimensional, que está compuesta por los elementos de actividad, apertura y posesión. La libertad es un concepto y una realidad análoga, no unívoca, como por el contrario se suele pensar. Los diferentes seres son libres cada uno a su manera. Eso quiere decir que la libertad es en cada ser el modo como éste es activo, abierto y poseedor. Pero un modo no es un núcleo constitutivo, lo que, a mi modo de ver, significa que la libertad, como decían los clásicos medievales, es una propiedad - y no sujeto, como afirma E. d'Ors, tan acertado otras muchas veces - pero a diferencia de la tesis medieval citada, habría que añadir que no es sólo propiedad de la voluntad, sino de todo el ser humano. Es decir, es más que una propiedad de una potencia, pero es menos que la "substancia" del ser humano.

Si la libertad fuera substancia o sujeto, habría que preguntarse porqué está, condicionada, "atada" por la naturaleza de sus accidentes o de sus propiedades, sin los cuales no puede actuar. Una libertad sería total, como ya queda dicho, si tuviera un poder completo sobre sus condicionantes, internos y externos, pero aun así no sería absoluta, pues sigue necesitando esa materia. 
Si consideramos, de otra parte, a la decisión como núcleo de la libertad humana, es claro que no puede ser absoluta, pues se decide entre posibilidades dadas y con condiciones internas dadas (pasiones, emociones, etc.). Tomada como tendencia, está determinada por su fin. Entendida como espontaneidad pura, puede ser la fuerza de la pasión sensible o de la razón pura, pero en ambos casos está formalizada por el modo de la pasión o de la razón. De otra parte, una fuerza pura que no sabe a dónde va porque carece de "formalización" alguna, no es nada. De resultas de todo ello, no es fácil sostener, frente a la intención última del pensamiento moderno, y de una buena parte del actual que se declara de "inspiración cristiana", que la libertad pueda ser lo nuclearmente constitutivo y distintivo, ni del ser humano ni de ningún otro ser, incluido Dios.

A mi modo de ver, S. A. Kierkegaard supo comprender como pocos el problema de la libertad humana. En sus textos de "La alternativa" lo deja transparecer con agudeza. "Don Giovanni" parece ser libre, pues pone en práctica su voluntad de poder en cada una de sus conquistas; pero no lo es. En realidad, sólo puede ser libre quien se autoposea, pero para ello es preciso conocerse a sí mismo, justamente lo que el conquistador no logra, pues está arrastrado fuera de si por la pasión, pero al faltarle amor verdadero no se le hace presente su interioridad. No hay autoconocimiento en el puro dominio. Aunque tampoco se puede alcanzar en la pura reflexión, porque en ella nos movemos en el plano teórico, mientras que el "yo" es siempre también práctico y la reflexión sobre lo práctico sigue siendo teoría. Por tanto, tampoco puedo lograr autoposeerme por medio de la reflexión.

El único camino que me queda entonces es salir fuera de mí de modo pleno y existencial, para poder gracias a ello entrar en mi - pues no hay dentro sin fuera- y encontrarme. Esa salida sucede sólo en el amor verdadero. Al salir sólo emocional o intelectualmente mi interioridad aún no comparece. A su vez, cuando tengo un amor inicialmente verdadero, pero aún no sometido a las adversidades de la vida temporal, todavía no es firme, y por ello no he acabado aún de "hacerme cargo" plenamente de mi mismo. 
Es en el sufrimiento de las adversidades y dificultades donde me encuentro y descubro a mi mismo del modo más profundo.

Agustín de Hipona lo vio con claridad: el "yo" que se ha empezado a descubrir a sí mismo, se encuentra de modo pleno al experimentar en el sufrimiento que él —su identidad personal— no es autosuficiente y sólo es "realmente real" — para decirlo en términos platónicos— en el amor eterno a Dios. La teoría de las "Tres memorias" agustiniana, replicada a su modo en la de los "Tres estadios existenciales" de Kierkegaard, me parece ser el culmen de la antropología.

Por tanto, el núcleo constitutivo y diferenciador del ser humano es su interioridad, que no se identifica con su intimidad - la cual puede ser sólo sentimental—, ni con su inteligencia — que no es existencial一, ni con su libertad - que es sólo una propiedad del ser humano-. Esa interioridad se ha expresado también por medio del concepto de corazón, cuando éste no se ha reducido — como, sin embargo, es habitual hoy- al mero querer sentimental. El concepto de corazón tal como aparece en la gran tradición neoplatónico-cristiana es la unidad nuclear de inteligencia, voluntad y sensibilidad, unidad que se realiza en el amor verdadero.

El "pecado contra el espíritu" de la filosofía moderna ha sido abandonar el concepto de corazón e intentar sustituirlo por la tripleta libertad absoluta - razón pura - sentimiento absoluto. Según las diversas tendencias dentro de la llamada "modernidad" se ha acentuado más una u otra de esas dimensiones, o bien se las ha intentado sintetizar. Pero una síntesis nunca es una unidad originante, como lo es, por el contrario, el amor verdadero. La cultura moderna carece de unidad, tanto en general como en su encarnación en cada individuo.

Esa falta de unidad no se puede arreglar mediante una simple interdisciplinaridad teórica. Esta es de gran interés, y bien difícil de hacer — por lo que de ella se habla mucho y se concreta poco-, pero no basta por sí sola para conseguir, por las razones antedichas, encontrar la unidad fundamental. Y eso afecta de la manera más aguda al conocimiento que el ser humano 
busca acerca de sí mismo. La antropología es hoy un mosaico de investigaciones de las variadas dimensiones del ser humano, pero la unidad no comparece.

Tercera posibilidad. La tercera opción consiste en afirmar que es posible un "diálogo" entre la libertad y sus condicionantes. Esa es la tesis "clásica" y tradicional cristiana: el ser humano es libre con respecto a lo que recibe, a lo que le es dado. Pero encuentra que esa "materia" no es informe, sino que está configurada, y que por consiguiente quien la ha hecho, la ha hecho así. La convicción de que lo dado es inteligible - pues no es informe- me conduce a la idea de que quien lo hizo me está diciendo algo a través de esa conformación. Si crear, es decir, la conformación de lo creado me está diciendo algo.

De ahí que, según esta tesis, el ser humano puede arreglar desperfectos y potenciar "desde" lo perfecto — tanto con respecto a sí mismo como con respecto a otras personas y a la naturaleza en general-, pero no debe jugar con la naturaleza (la naturaleza es lo dado y, por tanto, soy antecedido por ella, que es un "pasado transcendental"). Por eso en esa tesis se recalca el carácter fundamental de la idea de perfección: hay que "llevar a la perfección" lo defectuoso, y, a su vez, sólo es posible potenciar "desde la perfección". Pero potenciar no es cambiar, como transformar tampoco es cambiar la identidad, sino imprimirle novedad.

\section{La hipótesis evolucionista}

Hay un punto, con todo, en el que la antropología no se ha separado del pensar habitual de todo tiempo, a saber, el reconocimiento de que no nos hemos hecho a nosotros mismos. De ahí la insistencia, reflejada en los títulos de muchos libros: "Origen u orígenes del ser humano". Y como la razón pura no alcanza por medios exclusivamente lógicos a dar explicaciones del origen, hace falta echar mano de la ciencia empírica. Sin embargo, el empirismo puro no explica nada; la ciencia empírica ha de proceder, por ello, con 
hipótesis, y la que invade nuestra cultura actual es la hipótesis evolucionista.

No hay duda de que ha habido cambios a lo largo del tiempo. Hay una Historia de la Naturaleza, como la hay de los pueblos. Los Antiguos ya lo sabían, como lo sabía la Biblia, que en el Génesis describe la creación del mundo en pasos sucesivos. En esto, la novedad moderna está sólo en el detalle con el que se han ido descubriendo los acontecimientos de la historia natural. Pero la explicación de por qué suceden los cambios es aún bien rudimentaria. Y aunque se afirma que estamos en camino de averiguarlo, no sabemos aún cómo se podría haber dado el hipotético paso de una especie a otra.

Esto último afecta de manera especial a la "evolución" del ser humano. Cada fósil nuevo que aparece obliga a retocar la explicación científica de la secuencia, pero lo que no puede lograr esa investigación es situar en el tiempo el origen de la interioridad. Como se apuntaba al comienzo de este escrito, la libertad es un concepto y una realidad analógica, y lo mismo cabe decir en relación con las diferentes dimensiones del ser humano. Tenemos cuerpo físico, conocimiento, pasiones y emociones sensibles; también los animales, pero de diferente manera. Tenemos inteligencia teórica, práctica y técnica y voluntad; también los animales en otro nivel muy inferior. Nos duelen los golpes, como también a los animales e incluso a las plantas, en niveles muy inferiores.

Por ello, no es de extrañar que si se busca colocar lo analógico en forma de serie temporal - procedimiento del evolucionismo antropológico- surjan dificultades de todo tipo, dificultades que han conducido no pocas veces —hechos ciertos- a silenciar descubrimientos paleontológicos porque no "encajaban" en la secuencia evolutiva prevista. Pero la dificultad principal a partir de ese método es encontrar el fósil o los fósiles definitivos a los que se les pueda aplicar plenamente el nombre de humanos, diferenciados de todo lo anterior. 
Más aún: ¿cómo podemos estar seguros de que no va a cambiar —y tal vez a peor- el hombre actual? Cualquier día nos encontramos con la sorpresa de que una familia de chimpancés nos sobrepasa, mediante un "arreón" evolutivo, mientras que nosotros decaemos a la condición de primates, lo que tal vez no sería malo dadas las ideas morales del "homo sapiens" actual. Si la evolución funciona mediante el esquema "mutaciónadaptación" podemos esperar cualquier cosa, ya que si una mutación lo es de verdad no se puede explicar científicamente - la ciencia no puede hacer "saltos"- y la adaptación es cada vez más difícil de calcular dados los continuos y rápidos cambios en nuestro planeta.

\section{Conclusión}

Aparentemente, es más científico explicar este mundo y, sobre todo, el ser humano, sin acudir a referencias transcendentes. Con todo, qué produce el "big-bang", por qué cambia el mundo físico y cuál es el primer hombre o los primeros hombres, la ciencia no lo puede explicar por ahora, a no ser que se consideren explicaciones aludir a la nada inicial, las sorprendentes mutaciones o la casualidad de que un mono se vio obligado a erguirse a la vez que por suerte le crecía el cerebro. Resulta igual de científica, pero más metafísica, la teoría de la creación continua, e igual de científico, pero más consolador, pensar que un buen Padre celestial es el encargado.

Rafael Alvira Domínguez

ralvira@unav.es 